\title{
Excessive daytime sleepiness in patients with chronic kidney disease undergone hemodialysis
}

\author{
Sonolência excessiva diurna em pacientes com doença \\ renal crônica submetidos a hemodiálise
}

\author{
Nina Teixeira Fonsêca ${ }^{[a]}$, Israel R. Santos ${ }^{[a]}$, Virgilio Fernandes ${ }^{[b]}$, Vinicius Alves Thomaz Fernandes ${ }^{[b]}$, \\ Viviane Cristina Delgado Lopes $^{[\mathrm{b}]}$, Luis Vicente F. Oliveira ${ }^{[\mathrm{a}]}$ \\ [a] Universidade Nove de Julho (Uninove), Rehabilitation Sciences Master's and PhD Degree Program, Sleep Laboratory, Sao \\ Paulo, SP - Brazil, e-mails: ninatf_23@hotmail.com; ireissantos@uol.com.br; oliveira.lvf@uninove.br \\ [b] Centro de Nefrologia Zona Norte (Cenenorte), Sao Paulo, SP - Brazil, e-mails: fernandesvirg@uol.com.br; \\ vifernandes@hotmail.com; vivianelopes.enf@hotmail.com
}

\begin{abstract}
Introduction: Approximately $80 \%$ of patients with chronic kidney disease complain about sleep disorders, which is a much higher percentage than in the general population. Excessive daytime sleepiness is the third most frequent complaint in these patients, and it is significantly associated with a higher risk of sleep apnea. The aim of this study was to assess the presence of daytime sleepiness in patients with end stage renal disease (ESRD) who were undergoing diurnal hemodialysis. Materials and methods: The Epworth Sleepiness Scale (ESS) was applied to patients with ESRD who underwent diurnal hemodialysis in the Centro de Nefrologia da Zona Norte in Sao Paulo, Brazil. Results: A total of 168 patients were included in the study. According to the ESS, $31 \%$ presented with a mild propensity to sleep, $22 \%$ with a moderate propensity, and 17\% with a severe propensity. Conclusion: Our study concluded that $70 \%$ of the sample of patients with ESRD who were undergoing hemodialysis presented with a propensity to sleep in inappropriate circumstances on the ESS. When excessive daytime sleepiness is associated with sleep apnea and other comorbidities, it is essential to carefully assess patients' complaints.
\end{abstract}

Keywords: Sleep. Renal dialysis. Sleepiness. Chronic renal insufficiency.

Fisioter Mov. 2014 out/dez;27(4):653-60 


\section{Resumo}

Introdução: Aproximadamente $80 \%$ dos pacientes com doença renal crônica (DRC) referem alguma queixa sobre distúrbios do sono, sendo muito maior do que na população em geral. A sonolência excessiva diurna é a terceira queixa mais frequente e está significativamente associada com um maior rico de apneia do sono. o objetivo deste estudo foi avaliar a presença de sonolência excessiva diurna em pacientes com doença renal em estágio final (DREF) submetidos a hemodiálise diurna. Materiais e métodos: A escala de sonolência de Epworth (ESE) foi aplicada em pacientes em DREF, que realizam hemodiálise diurna no Centro de Nefrologia da Zona Norte, na cidade de São Paulo. Resultados: Cento e sessenta e oito pacientes foram incluídos no estudo. Trinta e um por cento da amostra apresentou uma leve propensão a dormir, de acordo com ESE, enquanto que vinte e dois por cento apresentaram uma moderada propensão e dezessete por cento apresentaram uma grave propensão. Conclusão: Nosso estudo concluiu que 70\% da amostra em DREF submetidos a hemodiálise apresentaram uma propensão de dormir em circunstâncias inapropriadas, de acordo com a escala de sonolência de Epworth. Uma vez que a sonolência excessiva diurna está associada com a apneia do sono e outras comorbidades é essencial estar atento às queixas desses pacientes

Palavras-chave: Sono. Diálise renal. Distúrbios do sono por sonolência excessiva. Insuficiência renal crônica.

\section{Introduction}

Complaints of sleep disturbances and excessive daytime somnolence are common in patients with chronic kidney disease. Approximately $80 \%$ of these patients have manifestations of sleep disorders, with the prevalence of sleep apnea reported to be $13 \%$ $70 \%$, which is much higher than in the general population $(1,2)$.

According to a previous study (3), numerous features, such as the high prevalence of primary sleep problems, selected demographic characteristics, diseases associated with metabolic abnormalities, and the effects of treatment, place patients at risk for sleepiness. Sleep disorders, including delayed sleep onset, frequent awakening, restless leg syndrome, insomnia, and daytime sleepiness, are frequent in patients with end stage renal disease (ESRD) (2, 4-8). These symptoms affect sleep quality and consequently the quality of life of these patients (9-11).

Excessive daytime sleepiness (EDS) is the propensity of an individual to sleep in circumstances that the affected individual and others consider inappropriate. EDS is the third most reported sleep disease in patients with ESRD after insomnia and day and night sleep reversal. EDS is mainly associated with a high risk of sleep apnea, but it could also be a consequence of insomnia, restless leg syndrome, and medical problems $(12,13)$.
The Epworth Sleepiness Scale (ESS) $(14,15)$, which was developed by Johns in 1991, has been widely used in research studies of sleep disorders to verify sleep propensity in eight daily situations. Thus, the purpose of this study was to assess the presence of daytime sleepiness using the ESS in patients with ESRD who were undergoing diurnal hemodialysis at a nephrology center in Sao Paulo, Brazil.

\section{Materials and methods}

This was a cross-sectional study of 168 patients with ESRD who were undergoing hemodialysis. The subjects were recruited from the Centro de Nefrologia da Zona Norte (Sao Paulo, Brazil) from March to October 2013.

We included male and female patients with chronic kidney disease who, were over 18 years of age, were candidates for a kidney transplant, were undergoing diurnal hemodialysis, had a cognitive level that was sufficient for understanding the procedures, and agreed to participate by signing the informed consent. We excluded patients who were undergoing treatment for sleep apnea, active psychiatric disease, or active alcohol and/or drug abuse or who refused to participate.

The participants underwent a clinical evaluation, which included assessments of body weight $(\mathrm{kg})$, height $(\mathrm{cm})$, and body mass index (BMI) (16). The data for gender, age, race, smoking, alcohol habits, 
occupation, months of treatment, main disease, and associated pathological conditions were obtained from medical charts.

The ESS $(15,17)$ was used to verify the presence of excessive daytime sleepiness. The ESS is a well-established questionnaire that aims to assess the presence of excessive daytime sleepiness in adults. The ESS is simple and self-administered and is composed of eight activities of daily living and sleep propensity. The same evaluator administered the questionnaires and patients having difficulty reading or writing were provided assistance.

Individuals answered the questionnaire using a scale from 0 to 3 , with 0 indicating no chance of napping and 3 indicating a strong chance of napping. According to Kryger et al. (18), patient ESS data were classified as normal for scores ranging from 0 to 8 , mild for scores ranging from 9 to 12 , moderate for scores ranging from 13 to 16 , and severe for scores over 17.

This study was conducted in accordance with the ethical standards established by the Declaration of Helsinki (1961), which was revised in Hong Kong in 1989 and Edinburgh, Scotland, in 2000, and in compliance with the Regulatory Guidelines and Norms for Research Involving the Health Board of the Brazilian Health Ministry in December 2012.

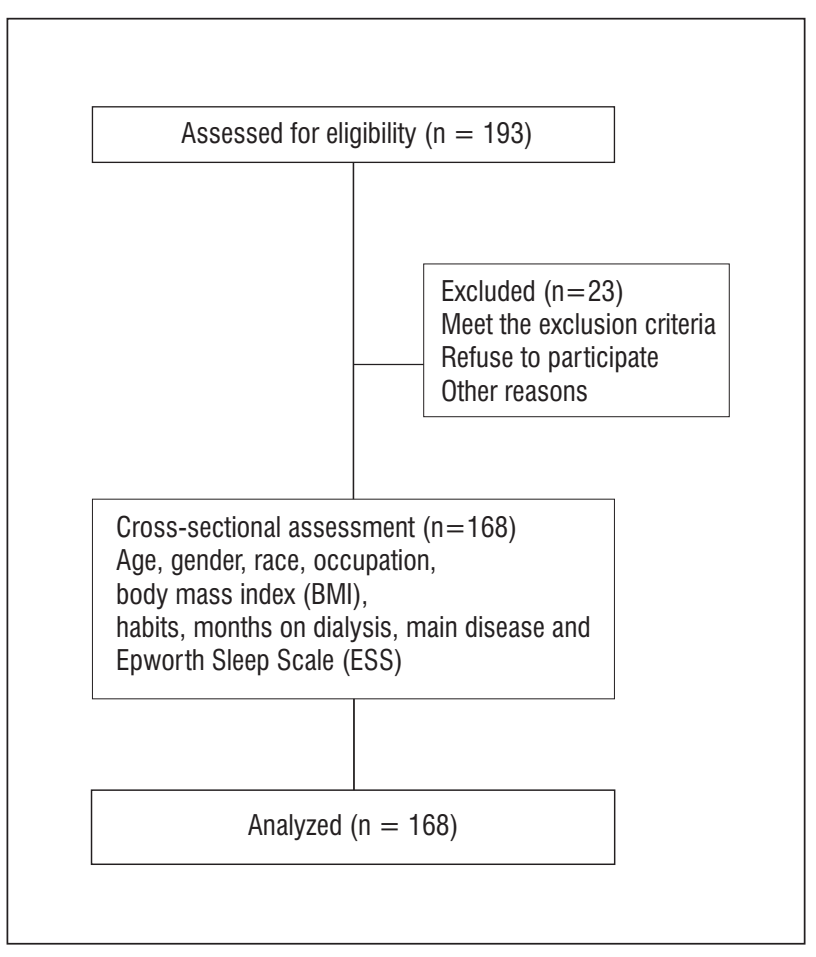

Figure 1 - Flowchart of the study
The protocol for this study was approved by The Human Research Ethics Committee of Universidade Nove de Julho (Sao Paulo, Brazil) with the protocol number 368856/2010, and it was registered with the Brazilian Registry of Clinical Trials (ReBEC RBR-7yhr4w and World Health Organization under Universal Trial Number UTN: U1111-11279390 [http://www.ensaiosclinicos.gov.br/rg/RBR$7 y h r 4 w /])(19)$.

The results of the study are shown as an absolute number, percent, or mean and standard deviation, as appropriate. The normality of the distribution was assessed by the Kolmogorov-Smirnov's Z-value test before the method of data analysis was determined. The data management and analyses were conducted using the Statistical Package for Social Sciences, version 20.0 (IBM Corporation, Armonk, NY, USA).

\section{Results}

A total of 193 patients were initially assessed for eligibility, but only 168 patients were included in the study after they signed the informed consent form. Twenty-three subjects were excluded for meeting the exclusion criteria, refusing to participate. The majority of patients underwent hemodialysis for $4 \mathrm{~h}$ three times a week in three shifts (morning, afternoon, and evening). The social and demographic characteristics are shown in Table 1, while the clinical characteristics are shown in Table 2.

It is important to highlight that some patients presented with multiple comorbidities. The other frequent comorbidities in these patients included polycystic kidney disease in seven patients, infection with human immunodeficiency virus in six patients, and pyelonephritis and hypothyroidism in four patients.

In our study, the patient ESS data were classified according to Krieger et al. (18) as normal [0-8], mild [9-12], moderate [13-16], or severe (>17). The results are shown in Figure 2.

\section{Discussion}

Complaints of sleep disorders are common in patients with ESRD. Multifactorial causes, including pathophysiologic factors, psychological factors, and lifestyle-related factors, are involved in the etiology of sleep disorders in patients undergoing hemodialysis. 
A review study by Perl et al. (20) examined the interactions between ESRD and sleep disorders. The authors found that EDS is common in patients with ESRD with or without sleep disorders; however, the pathogenesis of daytime sleepiness is likely multifactorial and might be due to day/night sleep reversal, which has often been cited as a cardinal feature of uremia.

In a study by Al-Jahdali (13), the presence of patients were considered positive for EDS if presented with an ESS score that was equal to or more than 10. This study assessed 227 patients with ESRD out of which 100 patients (44\%) presented with EDS. The author also reported that the prevalence of EDS was more frequent in patients undergoing peritoneal dialysis. This finding could not be compared to the results of the present study because we only assessed patients who were undergoing diurnal hemodialysis.
Bastos et al. (21) investigated the prevalence of EDS among 100 subjects who underwent hemodialysis in different shifts. A total of $28 \%$ of the sample presented with EDS, which was classified as present for ESS scores $\geq 10$ or absent for ESS scores $<10$. The percentage of patients presenting with EDS were $36 \%, 19 \%$, and $33 \%$ for patients undergoing dialysis in the morning, afternoon, and evening, respectively. These authors concluded that the presence of EDS was not influenced by the dialysis shift.

With the goal of determining sleep quality in patients undergoing hemodialysis, Čengić et al. (12) applied the Pittsburgh Sleep Quality Index (PSQI) (22) in 200 patients undergoing diurnal hemodialysis. They found that $73 \%$ of the patients showed poor sleep quality and several sleep disturbances in addition to EDS (34\%), including restless leg syndrome, nightmares, insomnia, and day and night sleep reversal.

Table 1 - Social and demographic characteristics data

\begin{tabular}{lcc}
\hline \multicolumn{1}{c}{ Characteristics } & $\mathrm{n}$ & $\%$ \\
\hline Age (years) & $56.6 \pm 14.82$ & \\
Weight & $69 \pm 15.78$ & \\
Gender & & 60 \\
Male & 101 & 40 \\
Female & 67 & \\
Race & & 65.5 \\
Causasian & 110 & 12 \\
African american & 20 & 22.5 \\
Other & 38 & \\
Employment status & & 67 \\
Employed & 113 & 33 \\
Unemployed & 55 & 34 \\
BMI categories & & 50 \\
Under weight (below 18.5) & 94 & 5 \\
Normal (18.5 - 24.9) & 97 & \\
Over Weight (25.0 - 29.9) & & \\
Obese (over than 30.0) & & \\
\hline
\end{tabular}


Table 1 - Social and demographic characteristics data

(Conclusion)

\begin{tabular}{lcc}
\hline \multicolumn{1}{l}{ Characteristics } & $\mathbf{n}$ & $\%$ \\
\hline Habits & 31 & 12.5 \\
Smoking & 10 & 6 \\
Alcohol intake & 10 & \\
\hline
\end{tabular}

Note: Age and weight were expressed by mean and standard deviation. Gender, race, Data were expressed in absolute numbers and percent.

Table 2 - Clinical characteristics

\begin{tabular}{|c|c|c|}
\hline Characteristics & $\mathrm{n}$ & $\%$ \\
\hline Urea (mg/dL) & $152.84 \pm 39.9$ & \\
\hline Albumin $(g / d L)$ & $3.83 \pm 0.48$ & \\
\hline Creatinine (mg/dL) & $11.16 \pm 4.16$ & \\
\hline Ferritin $(\mu \mathrm{g} / \mathrm{L})$ & $636.67 \pm 487.9$ & \\
\hline $\mathrm{Kt} / \mathrm{V}$ & $1.24 \pm 0.29$ & \\
\hline \multicolumn{3}{|l|}{ Months on hemodialysis } \\
\hline $0-12$ & 48 & 28.6 \\
\hline $13-24$ & 35 & 20.8 \\
\hline $25-36$ & 25 & 14.9 \\
\hline $37-48$ & 13 & 7.7 \\
\hline $49-60$ & 11 & 6.5 \\
\hline $61-72$ & 14 & 8.3 \\
\hline $73-84$ & 10 & 6 \\
\hline Over than 85 & 12 & 7.1 \\
\hline \multicolumn{3}{|l|}{ Main disease } \\
\hline Hypertension & 108 & 64.3 \\
\hline Diabetes mellitus & 67 & 40 \\
\hline Glomerulonephritis & 14 & 8.3 \\
\hline Nephrosclerosis & 17 & 10 \\
\hline Other & 41 & 24.4 \\
\hline
\end{tabular}

Note: Urea, albumin, creatinine, ferritin and Kt $\mathrm{V}$ were expressed by mean and standard deviation. Months on dialysis and main disease were expressed in absolute numbers and percent. 


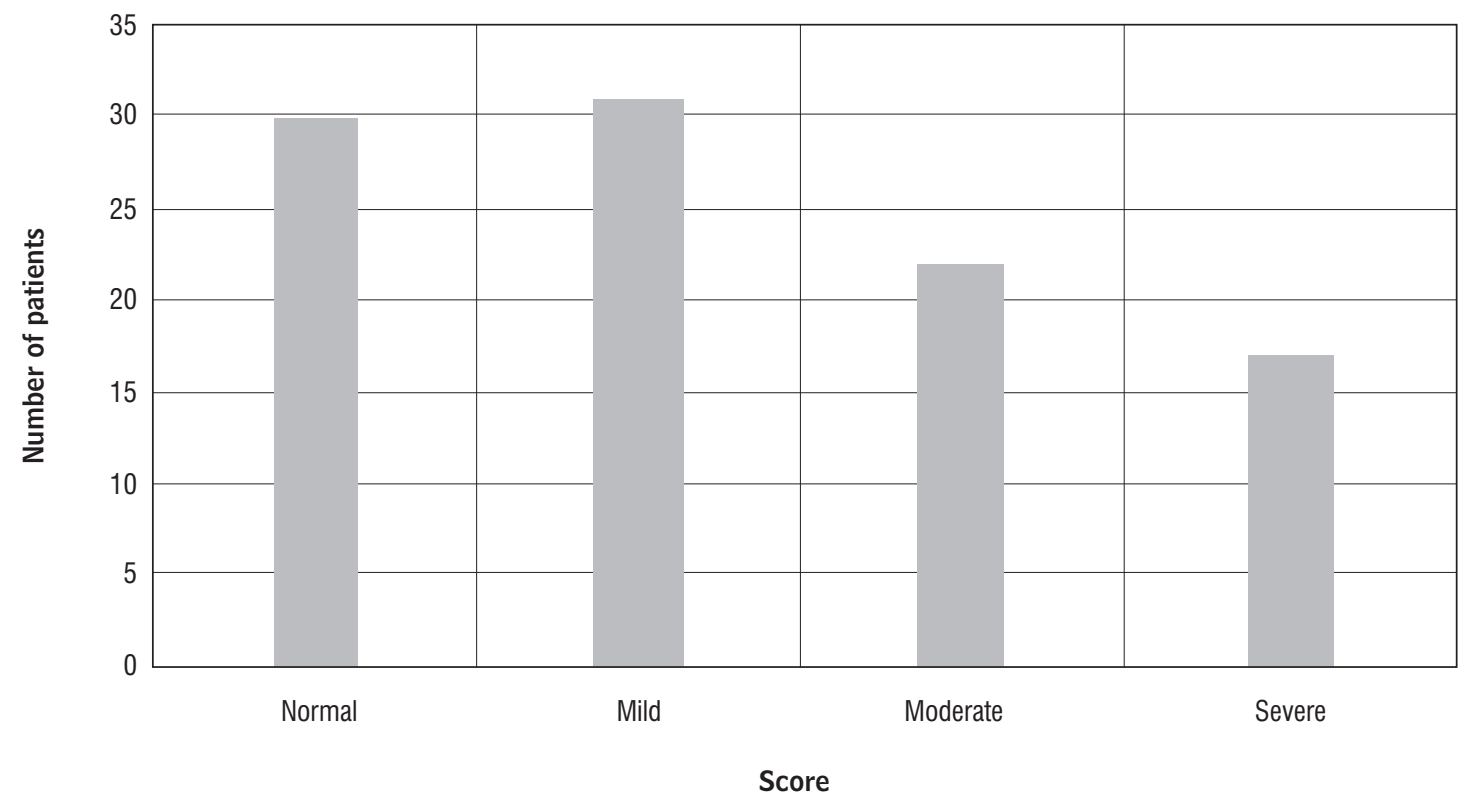

Figure 2 - Epworth Sleepiness Scale (ESS) results

The patients that study also exhibited snoring, pain, daytime napping, and breathing problems.

Edalat-Nejad et al. (10) used the PSQI and the Medical Outcomes Study 36-item Short Form (23) to determine the quality of life and sleep of 115 patients undergoing chronic hemodialysis. Eight-seven percent of the sample were considered "poor sleepers" according to the PSQI and presented with a low quality of life, especially with a mental health component.

Nocturnal hemodialysis is a new modality that enables patients to receive hemodialysis while they are sleeping at home 7 nights per week. It provides better clearance of uremic toxins and may reduce the daytime sleepiness associated with chronic renal failure. Hanly et al. (24) used the ESS to assess EDS in patients undergoing nocturnal hemodialysis. The results showed that, even with nocturnal hemodialysis, EDS is persistent and is possibly caused by periodic leg movements.

In the present study, $70 \%$ of our sample presented with some propensity to sleep in inappropriate situations according to the ESS. It is important to highlight that $39 \%$ of our sample presented with EDS scores that were between moderate and severe and that could be attributed to other sleep disturbances, especially sleep apnea. The presence of EDS, which was observed in most of our study sample, is a consequence of poor quality of sleep, which has also been observed in previous studies.

Regarding the etiology of chronic kidney disease and ESRD, the results of our study corroborate those of the studies by Roumelioti et al. (25), Elias et al. (26), and Araujo et al. (26) They found that diabetes, hypertension, and glomerulonephritis were the main causes of patients needing hemodialysis, and patients with these diseases made up at least 50\% of the sample.

Sleep disorders are highly prevalent in patients with chronic kidney disease. These disorders may contribute to cardiovascular disease and be responsible for the substantial morbidity and mortality found in this population (28). In our study, was the most frequent primary disease. This finding strengthens the statement by Sim et al. (29), that the causative association between chronic kidney disease and sleep disorders, especially sleep apnea, is unknown. That study suggested that the two diseases represent clinical sequelae of a more common disease process, such as hypertension or diabetes mellitus.

The study by Edalat-Nejad et al. (30) purpose do examined which factors affected sleep quality in 
patients with ESRD. The authors applied the PSQI in 138 patients with ESRD undergoing maintenance hemodialysis. Poor sleep quality was positively correlated with age, serum calcium levels, and diabetes mellitus as the underlying cause of renal failure. In the present study, diabetes mellitus was the second primary disease that resulted in ESRD in patients and patients with diabetes represented $40 \%$ of the sample.

\section{Conclusion}

Our study showed that $70 \%$ of patients with ESRD who were undergoing hemodialysis presented with a propensity to sleep in inappropriate circumstances, as assessed by the ESS. When excessive daytime sleepiness is associated with sleep apnea and other comorbidities, it is essential to carefully assess patients' complaints and include an overnight polysomnography as a routine test.

\section{Acknowledgments}

The Sleep Laboratory receives funding from the Nove de Julho University (Brazil) and research projects approved by the Brazilian fostering agencies Fundação de Amparo à Pesquisa do Estado de São Paulo (local acronym FAPESP; protocol no. 2003/01810-4) and Conselho Nacional de Desenvolvimento Científico e Tecnológico (local acronym CNPq; Research Productivity modality; process no. 307618/2010-2).

\section{References}

1. Walker S, Fine A, Kryger MH. Sleep Complaints are common in a dialysis unit. Am J Kidney Dis. 1995; 26(5):751-6.

2. Merlino G, Piani A, Dolso P, Adorati M, Cancelli I, Valente $\mathrm{M}$, et al. Sleep Disorders in patients with end-stage renal disease undergoing dialysis therapy. Nephrol Dial Transplant. 2006;21(1):184-90.

3. Parker KP, Bliwise DL, Bailey JL, Rye DB. Daytime sleepiness in stable hemodialysis patients. Am J Kidney Dis. 2003;41(2):394-402.
4. Sabry AA, Abo-Zenah H, Wafa E, Mahmoud K, El-Dahshan K, Hassan A, et al. Sleep disorders in hemodialysis patients. Saudi J Kidney Dis Transpl. 2010;21(2):300-5.

5. Al-Jahdali H. A Comparison of sleep disturbances and sleep apnea in patients on hemodialysis and chronic peritoneal dialysis. Saudi J Kidney Dis Transpl. 2011;22(5):922-30.

6. Aritake-Okada S, Nakao T, Komada Y, Asaoka S, Sakuta K, Esaki S, et al. Prevalence and clinical characteristics of restless legs syndrome in chronic kidney disease patients. Sleep Med. 2011;12(10):1031-3

7. Hanly P. Sleep disorders and home dialysis. Adv Chronic Kidney Dis. 2009;16(3):179-88.

8. Szentkiralyia A, Molnara MZ, Cziraa ME, Deakc G, Lindnera AV, Szeiferta L, et al. Association between restless legs syndrome and depression in patients with chronic kidney disease. J Psychosom Res. 2009;67(2):173-80.

9. Edalat-Nejad M, Qlich-Khani M. Quality of life and sleep in hemodialysis patients. Saudi J Kidney Dis Transpl. 2013;24(3):514-8.

10. Sabbatini M, Pisani A, Crispo A, Ragosta A, Gallo R, Pota $A$, et al. Sleep quality in patients with chronic renal failure: a 3-year longitudinal study. Sleep Med. 2008;9(3):240-6.

11. Roumelioti ME, Argyropoulos C, Buysse DJ, Nayar H, Weisbord SD, Unruh ML. Sleep quality, mood, alertness and their variability in CKD and ESRD. Nephron Clin Pract. 2010;114(4):277-87

12. Čengić B, Resić H, Spasovski G, Avdić E, Alajbegović A. Quality of sleep in patients undergoing hemodialysis. Int Urol Nephrol. 2012;44(2):557-67.

13. Al-Jahdali H. Prevalence of sleep apnea and excessive day time sleepiness in patients with end-stage renal disease on dialysis. Saudi J Kidney Dis Transpl. 2012;23(2):251-61.

14. Johns MW. A new method for measuring daytime sleepiness: the Epworth sleepiness scale. Sleep. 1991;14(6):540-5. 
15. Johns MW. Sensitivity and specificity of the multiple sleep latency test (MSLT), the maintenance of wakefulness test and the Epworth sleepiness scale: failure of the MSLT as a gold standard. J Sleep Res. 2000; 9(1):5-11.

16. Punjabi N.: The epidemiology of adult obstructive sleep apnea. Proc Am Thorac Soc. 2008,5(2):136-43.

17. Bertolazi AN, Fagondes SC, Hoff LS, Pedro VD, Barreto SSM, Johns MW. Validação da escala de sonolência de Epworth em português para uso no Brasil. J Bras Pneumol. 2009;35(9):877-83.

18. Kryger MH, Roth T, Dement WC. Principles and practice of sleep medicine. 4th ed. Philadelphia: Elsevier/ Saunders; 2005.

19. Santos IR, Danaga AR, Aguiar IC, Oliveira EF, Dias IS, Urbano JJ, et al. Cardiovascular risk and mortality in end-stage renal disease patients undergoing dialysis: sleep study, pulmonary function, respiratory mechanics, upper airway collapsibility, autonomic nervous activity, depression, anxiety, stress and quality of life: a prospective, double blind, randomized controlled clinical trial. BMC Nephrol. 2013;14:215.

20. Perl J, Unruh ML, Chan CT. Sleep disorders in endstage renal disease: 'Markers of inadequate dialysis?' Kidney Int. 2006;70(10):1687-93.

21. Bastos JPC, Sousa RB, Nepomuceno LAM, GutierrezAdrianzen AO, Bruin PFC, Araujo MLLB, et al. Sleep disturbances in patients on maintenance hemodialysis: role of dialysis shift. Rev Assoc Med Bras. 2007;53(6):492-6.

22. Buysse DJ, Reynolds CF 3rd, Monk L, Berman SR, Kupfer DJ. The Pittsburgh sleep quality index: a new instrument for phychiatric practice and research. Psychiat Res. 1989;28(2):193-213.

23. Ware JE Jr., Snow KK, Kosinski M, Gandek B. SF-36 health survey: manual and interpretation guide. Boston: The Health Institute; 1993.

24. Hanly PJ, Gabor JY, Chan C, Pierratos A. Daytime sleepiness in patients with CRF: impact of nocturnal hemodialysis. Am J Kidney Dis. 2003;41(2):403-10.

25. Roumelioti ME, Buysse DJ, Sanders MH, Strollo P, Newman AB, Unruh ML. Sleep-disordered breathing and excessive daytime sleepiness in chronic kidney disease and hemodialysis. Clin J Am Soc Nephrol. 2011;6(5):986-94.
26. Elias RM, Chan CT, Paul N, Motwani SS, Kasai T, Gabriel JM, et al. Relationship of pharyngeal water content and jugular volume with severity of obstructive sleep apnea in renal failure. Nephrol Dial Transplant. 2013;28(4):937-44.

27. Araujo SM, de Bruin VM, Nepomuceno LA, Maximo ML, Daher EF, Correia Ferrer DP, et al. Restless legs syndrome in end-stage renal disease: Clinical characteristics and associated comorbidities. Sleep Med. 2010;11(8):785-90.

28. Mavanur M, Sanders M, Unruh M. Sleep disordered breathing in patients with chronic kidney disease. Indian J Med Res. 2010;131:277-84.

29. Sim JJ, Rasgon SA, Derose SF. Review article: Managing sleep apnoea in kidney diseases. Nephrology. 2010;15(2):146-52

30. Edalat-Nejad M, Jafarian N, Yousefichaijan P. Diabetic nephropathy: a strong predictor of sleep quality in hemodialysis patients. Saudi J Kidney Dis Transpl. 2014;25(4):774-80.

Received: 05/13/2014

Recebido: 13/05/2014

Approved: 10/21/2014

Aprovado: 21/10/2014 